\title{
Responsabilidade e sentimento de culpa: uma vivência paradoxal dos profissionais de terapia intensiva pediátrica
}

Tereza Cristina Peixoto(a)

Izabel Christina Friche Passos ${ }^{(b)}$

Maria José Menezes Brito(c)

Peixoto TC, Passos ICF, Brito MJM. Responsibility and guilt: paradoxical feelings among professionals from a pediatric intensive care unit. Interface (Botucatu). 2018; 22(65): 461-72.

The objective of this study was to analyze the nature of responsibility at work among health professionals in a pediatric intensive care unit. This qualitative research involved data gathering from semi-structured interviews with a heterogenous group of 14 professionals. Systematic observations were carried out at different working hours, across a total of eighty hours, and were registered in a logbook. Discourse analysis was based on Foucault. The study showed that the feeling of responsibility is converted into a feeling of guilt by health professionals, based on the intermeshing of truth systems that draw on the fields of legal power, Christianity and medical knowledge, all of which impact on the individual's practices. The difficulties in dealing with limits in the professional sphere lead to conflicts between professionals which cause suffering when it comes to dealing with the death of children.

Keywords: Interprofessional relations. Professional responsibility. Professional ethics.
O objetivo deste estudo foi analisar a constituição da responsabilidade no trabalho de profissionais de saúde em uma unidade de terapia intensiva pediátrica. A pesquisa é de abordagem qualitativa, com coleta de dados mediante entrevistas com roteiro semiestruturado a um grupo heterogêneo de 14 profissionais. Foram realizadas observações sistemáticas em diversos horários de trabalho, em um total de oitenta horas, registradas em diário de bordo. A análise do discurso fundamentouse na perspectiva foucaultiana. A partir deste estudo, aponta-se que o sentimento de responsabilidade é convertido em sentimento de culpa pelos profissionais, a partir de um entrelaçamento de regimes de verdades provenientes dos campos do poder judiciário, do Cristianismo e do saber médico, que incidem sobre as práticas. As dificuldades em lidar com limites na atuação profissional desencadeiam conflitos interprofissionais geradores de sofrimento no lidar com a morte de crianças.

Palavras-chave: Relações interprofissionais. Responsabilidade profissional. Ética profissional.

\footnotetext{
(a) Centro Universitário UNA, Departamento de Psicologia, Instituto de Ciências Humanas. Rua Bogotá, n 383, apto. 202, Jardim América. Belo Horizonte, MG, Brasil. 30421-392. terezacpc@hotmail.com

(b) Departamento de Psicologia, Faculdade de Filosofia e Ciências Humanas, Universidade Federal de Minas Gerais (UFMG). Belo Horizonte, MG, Brasil. izabelfrichepassos@ gmail.com

(c) Departamento de Enfermagem Aplicada, Escola de Enfermagem, UFMG. Belo Horizonte, MG, Brasil. mj.brito@globo.com
} 


\section{Introdução}

O aumento da responsabilidade e da autonomia dos profissionais de saúde é exigência para a qualidade e humanização da assistência, considerando participação na gestão e vinculação com os

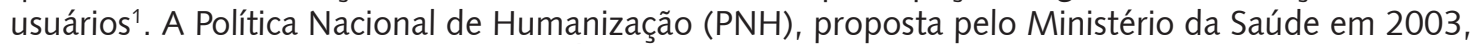
objetiva o fortalecimento do Sistema Único de Saúde (SUS) a partir da valorização de novos modos de subjetividade tanto nas práticas assistenciais quanto na gestão². Espera-se que a assistência seja norteada pelo conceito ampliado de saúde que considera os determinantes sociais do processo de saúde e doença e pela democratização nos serviços. A cultura da humanização valoriza o diálogo, a inventividade e a solidariedade nas relações entre profissionais, usuários e gestores ${ }^{1}$.

A PNH aponta ainda a importância de uma formação profissional com compromisso éticoestético-político. A dimensão ética se refere à defesa da vida de todos os sujeitos, com respeito às singularidades e às diferenças; a dimensão política corresponde à democratização das relações; e a dimensão estética, à inventividade nas práticas assistenciais, com ampliação das normas e possibilidades de vida para os usuários ${ }^{1}$.

Essa cultura, defendida pela $\mathrm{PNH}$, difere da que predomina nas relações entre os sujeitos na sociedade atual, caracterizada pelo capitalismo integrado e predomínio do saber medicalizante. No mundo moderno, os dispositivos de governo são difusos e objetivam a produção de modos de subjetividades, ou seja, modos de os indivíduos verem o mundo e a si mesmos e de se relacionarem. Esses dispositivos são construídos a partir da aliança do Estado com os saberes da ciência, em especial da Medicina, da Epidemiologia, da Psicologia, da Economia, entre outros. A partir desses saberes, o Estado prescreve modos de viver para a população, em prol da longevidade e da qualidade de vida, assegurando os direitos sociais, e, ao mesmo tempo, regulando os modos de viver ${ }^{3}$.

Ademais, as mudanças dos valores morais na modernidade apontam para o momento em que os interesses político-econômicos difundem identidades fixas, comportamentos consumistas, ideais de perfeccionismo e individualismo ${ }^{4}$. Os discursos do SUS e dos novos dispositivos do governo se encontram em constantes disputas e negociações com outras lógicas que compõem o campo híbrido do trabalho em saúde, como a judicialização, a formação de recursos humanos, entre outras.

Em outra direção, no campo jurídico, a responsabilização profissional tem sido enfatizada de modo crescente nos últimos anos ${ }^{5}$. Compreende-se que o dever do Estado em assegurar saúde e dignidade de vida à população tem intensificado a regulação sobre os serviços prestados a esta. Ademais, outros fatores contribuem para o aumento das denúncias judiciais contra os profissionais, como o aumento da conscientização dos cidadãos; a má relação de alguns médicos com seus pacientes e os interesses de mercado visando ao pagamento de indenizações ${ }^{5}$.

A produção da autonomia, na perspectiva da $\mathrm{PNH}$, requer alteridade e reconhecimento das diferenças, que são possíveis mediante reflexão crítica dos sujeitos. A autonomia é condição para uma postura da ética da responsabilidade, que compromete o sujeito com os riscos de suas escolhas ${ }^{1}$. No entanto, apesar da importância da autonomia e da responsabilidade, esperadas nos serviços de saúde, as práticas assistenciais e de gestão ainda configuram um campo produtor de comportamentos pouco participativos e comprometidos dos sujeitos ${ }^{6}$.

A partir desse contexto, entendemos que as exigências de autonomia e responsabilidade dispostas na atualidade são paradoxais, podendo representar novas técnicas de manipulação e objetivação dos sujeitos, inclusive com o emprego da judicialização, que, ao mesmo tempo, assegura os direitos dos usuários, mas favorece a subjugação dos profissionais.

Considerando esse contexto, problematiza-se como se constitui o sentimento de responsabilidade em um setor, como o da Unidade de Terapia Intensiva Pediátrica (UTIP), em que os profissionais lidam com situações-limite: o cuidado de crianças em condição crítica, com práticas de tratamento invasivas e medicalizantes que também as expõem a eventos adversos. Nessa direção, o objetivo deste estudo foi analisar a constituição da responsabilidade profissional no trabalho em uma UTIP.

Acreditamos que esta pesquisa se alinha às investigações que analisam a micropolítica do trabalho em saúde para a produção de novos modos de subjetividade no campo da Saúde Pública, norteados pelos princípios do SUS? Interessa-nos estimular novas problematizações que originem posturas éticas que favoreçam a humanização, a qualidade e a saúde no trabalho nas UTIP. 


\section{Metodologia}

Esse é um estudo que se apoia na abordagem qualitativa ${ }^{8}$. Trata-se de uma modalidade de estudo de caso, com análise em profundidade de uma unidade de saúde. Seguindo a teorização foucaultiana, buscou-se a análise dos saberes e práticas que sustentam os comportamentos éticos dos sujeitos.

O cenário de estudo foi a UTIP de um hospital universitário. A referida unidade foi escolhida por sua complexidade, uma vez que envolve alta tecnologia, saberes estruturados das diversas especialidades profissionais e, ao mesmo tempo, demandas subjetivas das crianças, de seus pais e dos próprios profissionais. Esse é um setor que favorece a análise das implicações éticas de responsabilização dos profissionais diante de um trabalho que envolve situações de alta vulnerabilidade, ao mesmo tempo que é controlado pela tecnologia e protocolos clínicos estritos.

A pesquisa foi aprovada pelos Comitês de Ética e do referido hospital onde o estudo foi desenvolvido. Foram seguidas todas exigências estabelecidas na resolução do Conselho Nacional de Saúde Brasileiro n. 466/12. A apresentação literal dos trechos transcritos das entrevistas foi identificada pela inicial de cada profissão.

A pesquisa ocorreu no período de junho a agosto de 2015. A coleta de dados foi feita por meio de observações do processo de trabalho, da dinâmica do setor e das relações interpessoais, registrados no Diário de Bordo (DB), com um total de 120 páginas; além de entrevistas com roteiro semiestruturado a um grupo heterogêneo de profissionais de saúde, com participação de dois médicos, duas enfermeiras, quatro técnicas de enfermagem, dois fisioterapeutas, um terapeuta ocupacional, uma psicóloga, um nutricionista, um coordenador médico e um coordenador da enfermagem, perfazendo 15 profissionais. As enunciações das entrevistas serão apresentadas com as iniciais da profissão e numeração dos profissionais, para a preservação do anonimato. Os fragmentos discursivos das observações serão apresentados pelas iniciais $\mathrm{DB}$, seguido da paginação do diário.

As perguntas norteadoras foram sobre como é trabalhar na unidade, como é o lidar com crianças doentes, como são as relações interprofissionais, quais são os fatores que dificultam e facilitam o trabalho na UTIP, como é o trabalho em equipe, como são as reuniões interprofissionais, que efeito o trabalho na UTIP provoca na vida dos profissionais.

A análise do discurso se fundamentou na perspectiva foucaultiana. Identificamos, inicialmente, os enunciados que compõem as formações discursivas que transversalizam as práticas no setor, a saber: o saber médico, o Cristianismo e a judicialização das práticas médicas. As formações discursivas são regras anônimas e históricas e abrangem verdades e práticas disciplinares em determinado momento socio-histórico ${ }^{9}$. Os resultados e sua discussão serão apresentados considerando-se os eixos analíticos: micropolítica das relações interprofissionais e o saber médico; e o Cristianismo.

\section{Micropolítica das relações interprofissionais}

O setor da UTIP é altamente regulamentado e normatizado por leis, protocolos clínicos, instruções de trabalho e registros contínuos dos procedimentos. O saber médico é o que predomina e fundamenta as práticas e protocolos, o que justifica também a centralidade do poder de decisão terapêutica desses profissionais.

Com relação ao saber e poder médico, sua autonomia profissional construída ao longo do século XIX confere liberdade de ação a esses profissionais no processo de trabalho, com igual posição de autoridade social e político-ideológica sobre a saúde e o adoecer, tanto na ciência quanto nos valores morais. No entanto, a partir do desenvolvimento científico e da inserção tecnológica e institucional do médico, produziram-se constrangimentos na liberdade de ação conquistada. A atuação do profissional médico em uma instituição exige sua adesão a um conjunto tecnológico que abrange aparelhos sofisticados e protocolos clínicos fundamentados em evidências científicas ${ }^{10}$.

Essa configuração do processo de trabalho médico, diferentemente do espaço do consultório, restringe sua autonomia em relação à condução clínica do paciente e às singularidades dos casos. Salienta-se que a atuação do médico envolve sempre um certo empirismo na medida em que a ciência não abrange as especificidades dos casos. Esses profissionais vivenciam um dilema entre respaldar seus atos decisórios pelo predomínio da técnica e evidência científica ou aliar a técnica à ética, considerando 
os encontros com os pacientes e demais profissionais para refletir criticamente a respeito das decisões a serem tomadas ${ }^{11}$. Nesse último modo de ação, o profissional se fortalece, pois conta com a participação de outros atores na proposta terapêutica. Na UTIP em estudo, foi observado que os médicos mantêm boa relação e comunicação da terapêutica com os pais das crianças e, ao mesmo tempo, respaldam seus atos em protocolos clínicos.

Nesse cenário, a autonomia dos médicos é também regulada pelo aumento de denúncias judiciais dos usuários contra os profissionais de saúde, que impacta nas relações dos profissionais com os usuários e dos profissionais entre si, no trabalho em equipe. Evidencia-se que as relações conflituosas entre médicos e usuários favorecem o aumento dessas denúncias por parte dos usuários ${ }^{5}$. No contexto jurídico, a responsabilidade é uma cobrança legal, exposta a conflitos.

Essa situação é intensificada no trabalho na UTIP, por envolver o lidar com crianças em situação de criticidade, o que faz com que os profissionais se tornem ainda mais vulneráveis, em suas práticas profissionais, em face dos eventos iatrogênicos. Tais eventos são provocados de modo indesejável pela própria terapêutica. Esse fato contribui para sentimentos de intensa cobrança dos profissionais consigo mesmos e com os demais, como também pela sociedade ${ }^{11}$.

Entendemos que o trabalho em saúde tem se tornado ainda mais complexo e paradoxal diante da disputa dos interesses corporativos, empresariais, da defesa dos direitos dos cidadãos que devem ser assegurados pelo Estado ${ }^{12} \mathrm{e}$, ao mesmo tempo, da complexidade da terapêutica. Para a proteção dos cidadãos perante os riscos advindos dos tratamentos de saúde, as leis que regulamentavam a profissão dos médicos e dos demais profissionais modernizaram-se na direção de assegurar os direitos humanos e a dignidade da vida. O paciente, enquanto cidadão, projeto do Estado Liberal, dispõe de vários mecanismos legais para sua proteção, como o Código de Defesa do Consumidor (CDC) e os juizados especiais cíveis e criminais para o julgamento das infrações de menor potencial ofensivo ${ }^{12}$.

Ante os processos de defesa do consumidor, o erro médico tem sido alvo de controle e denúncias, o que também representa uma instituição que alimenta a indústria de indenizações. A exigência da responsabilidade profissional para a qualidade do atendimento e segurança dos procedimentos terapêuticos é o que se convencionou para satisfazer a responsabilidade legal e o cumprimento das cláusulas contidas na Lei do Exercício Profissional, apesar de nenhum código de ética conseguir abranger os dilemas éticos vivenciados diante do desenvolvimento científico e tecnológico ${ }^{12}$.

O crescente número de denúncias judiciais por parte dos usuários é desencadeado pelo aumento da conscientização da população sobre seus direitos, mas também pela influência de interesses corporativos $^{5}$. No entanto, o mecanismo judicial de cobrança de responsabilidade do profissional para atender às exigências do governo e dos usuários dificulta a autonomia do profissional ${ }^{11}$. A subjetividade produzida nesse contexto normativo, com regras e ações prescritas e coercitivas, dificulta escolhas autônomas e responsáveis dos profissionais perante tomadas de decisão. As decisões fundamentadas somente nas normas descomprometem o profissional que se defende pelo cumprimento de normas e protocolos clínicos ${ }^{11}$.

Salienta-se que os referenciais normativos e de responsabilidade legal exigidos na UTIP produzem modos de pensar que favorecem conflitos, como no relato desta enfermeira: "[...] Os médicos de lá são pessoas que têm características fortes e são muito exigentes, mas usam de um... poder médico pra amedrontar e aterrorizar as pessoas" (E. 3).

Como resultado da tensão no exercício profissional dos médicos com relação ao tratamento, evidenciam-se comportamentos com busca acirrada por controle sobre os processos de trabalho dos demais profissionais ${ }^{13}$. Esse aspecto fragiliza a integração da equipe, além de favorecer sofrimento no trabalho.

Na UTIP, há centralidade do saber médico, com ênfase na estabilização dos padrões orgânicos para assegurarem a manutenção da vida das crianças. Tais saberes provenientes da ciência positivista sustentam as práticas de qualidade assistencial a partir de protocolos e diversos mecanismos de controle dos processos de trabalho ${ }^{13}$. Entendemos que esse é um território organizado, similar ao campo disciplinar jurídico, com saberes e mecanismos de vigilância e controles sofisticados.

As relações entre os sujeitos são modeladas em um compacto dispositivo disciplinar composto em um espaço fechado, com vigilância contínua, em que os profissionais têm funções e práticas definidas, 
com uma estrutura hierárquica constante no exercício profissional ${ }^{14}$. Nesse contexto, na UTIP, são produzidos comportamentos culpabilizantes e amedrontadores nos profissionais.

Esse sistema de vigilância passa a fazer parte do comportamento do próprio profissional consigo e com os outros, responsabilizando os profissionais perante as situações inesperadas ou de fracasso terapêutico. Na busca desenfreada por estabilização orgânica das crianças, o fracasso terapêutico ou a morte são associados à incompetência profissional, e não à impossibilidade de cura. A esse fato, acrescentam-se os dilemas éticos dos profissionais perante a decisão de interromper o investimento na cura das crianças. Ressalta-se a importância do fortalecimento da equipe de profissionais no enfrentamento dessas situações e da qualidade da assistência ${ }^{15}$.

Outro aspecto importante que se relaciona com o fracasso nos procedimentos refere-se à diversidade de vínculos profissionais e condições precárias de trabalho que impactam na dinâmica dos cuidados e no sofrimento dos profissionais. A esse respeito, na época deste estudo, o setor possuía diversos vínculos profissionais e contratos precários de trabalho, pois aguardavam a contratação dos aprovados em um concurso público, que regularizaria essa situação. A enfermagem, em especial, encontrava-se fragilizada, pois, além da diversidade de vínculos, possuía profissionais recém-contratados, admitidos muitas vezes sem treinamento adequado em função da alta rotatividade no setor.

Em contrapartida, a equipe médica estava coesa e organizada. Ela conseguiu elaborar seus protocolos clínicos, discutia casos e estudava com os residentes, o que contribuía para o fortalecimento desse grupo. Essa disparidade entre os grupos favorecia o aumento do controle dos médicos sobre o trabalho da enfermagem e dos demais profissionais, como exemplificado na enunciação do $M$. 1: "Antes tinha uma desorganização grande da equipe médica; quando isso organizou, que se montou protocolo, começou a criar um abismo muito grande entre o que a equipe médica queria e o que a enfermagem é capaz de oferecer" (M. 1).

A organização do trabalho também dificultava a integração da equipe, apesar do reconhecimento da importância da horizontalização do poder decisório entre os profissionais para a construção da interdisciplinaridade ${ }^{6}$.

Na UTIP em estudo, havia diversos vínculos empregatícios, com diferentes remunerações, distintas cobranças e controle hierárquico. A esse respeito, um dos médicos relatou: "[...] os médicos não estão ganhando tão bem, mas médico ganha bem melhor do que o restante das profissões. Eu sinto que parte das pessoas não consegue ter uma dedicação grande porque não se sentem confortáveis com o que ganham" (M. 2).

Entendemos que há importância atribuída ao dinheiro, como um dispositivo de vigilância do Estado que regula as relações entre os profissionais na UTIP. Nesse contexto, há necessidade de saberes técnicos altamente especializados.

Na micropolítica das relações no hospital, os médicos têm mais autonomia sobre seus atos e demandam e regulam o trabalho dos demais profissionais de saúde sem serem regulados em contrapartida $^{16}$. Paradoxalmente, em momentos de responsabilização por eventos inusitados no tratamento, os médicos buscavam compartilhar algumas responsabilidades, como no exemplo a seguir:

Quem vai contar para a família é a enfermagem, pois se aconteceu uma falha tem que falar. Mas acontece que as pessoas sempre acham que essa fala é de acusação, e não é. Quantas vezes a gente tentava; o médico é que tinha que ir lá e dar todas as notícias? Não damos conta de fazer isso e vamos dividir a responsabilidade. (M. 3)

Em face da responsabilização dos médicos perante as denúncias judiciais, emergem discussões polêmicas em torno do ato médico, com divisão da responsabilidade do cuidado com a equipe de profissionais de saúde. Entende-se que esse clima de tensão, a hierarquia médica e empecilhos para a integração efetiva da equipe expõem os médicos a responderem pelos danos ocorridos no tratamento.

$\mathrm{Na}$ esteira das preocupações com relação aos processos de trabalho e da responsabilidade perante a saúde das crianças, alguns médicos exageravam o controle sobre o trabalho dos demais, fragilizando ainda mais a equipe, como exemplificado nesta enunciação: "Teve uma época que tivemos uma médica lá no hospital, lá na UTIP, que orientou os pais a nos vigiar, vigiar a enfermagem" (T. 3). 
A vigilância sobre o trabalho dificulta a autonomia dos profissionais, a integração da equipe interprofissional e gera sofrimento ${ }^{13}$, como no relato a seguir: "E a gente tem que pegar e conversar com quem tá chorando muito, e que não aguenta mais. Porque eles tão em cima, se der uma deslizada eles tão em cima" (E. 2).

Esse relato se refere ao sofrimento dos técnicos de enfermagem com os médicos.

As técnicas e os técnicos de enfermagem se tornam mais expostos aos erros e cobranças por parte dos médicos por lidarem continuamente com as crianças e seus pais, executando prescrições médicas e de cuidados com crianças gravemente enfermas. Uma pesquisa sobre a produção de subjetividade na experiência de si da enfermeira evidencia que a enfermagem na unidade de terapia intensiva representa a extensão do braço do médico, uma vez que suas práticas se fundamentam no campo de saber desses profissionais ${ }^{17}$.

Ademais, durante a observação, em alguns momentos verificaram-se situações em que a falta de materiais dificultava o trabalho e gerava sofrimento, como na seguinte descrição:

A fisioterapeuta pediu para a enfermeira lhe dar uma sondinha para aspirar a criança, que estava com muita secreção, dizendo: "Pode ser uma sonda de número 06, pois a de número 08 não tem há uma semana". Nesse momento, uma técnica de enfermagem $Y$ disse: "Toma aqui, para você não falar que nunca te dei nada". (DB, p. 28)

Os profissionais, às vezes, compram o material que necessitam para o trabalho. Uma médica relatou durante a observação: "Quantas vezes a gente foi à farmácia e comprou o remédio que a criança precisava? Não foi somente uma vez. A gente deveria ter o material que precisamos para o trabalho (DB, p. 77).

Em outros momentos, os profissionais improvisavam o material, substituindo-o por outro semelhante. A improvisação gera insegurança nos profissionais com relação à eficácia, além de ser fonte de angústia ${ }^{18}$. Esse fato, associado à falta de técnicas de enfermagem por licenças médicas ou absenteísmos, como relatado pela coordenadora, expunha esses profissionais a erros nos procedimentos.

No enfrentamento das relações conflituosas desencadeadas nesse contexto, foi observado que as técnicas de enfermagem se apropriam dos mesmos mecanismos de vigilância que as controlam, para se protegerem. Na observação:

Os técnicos de enfermagem anotam constantemente tudo o que ocorre. Na rotina de trabalho realizam intervenções nas crianças; em seguida, assentam e registram o que foi realizado. Quando indaguei sobre a importância desse registro, uma técnica respondeu: "A gente registra tudo o que fazemos e assim a gente fica mais protegida. Tem que registrar mesmo, até com o nome dos médicos que prescreveram". (DB, p. 15)

Esse comportamento é correlato às exigências dos saberes jurídicos que necessitam de evidências para a defesa dos profissionais. O dispositivo da escrita nos mecanismos disciplinares, a partir de registros, faz de cada indivíduo um caso, que o representa tal como pode ser descrito, mensurado e comparado a outros, permitindo evidência e visibilidade ${ }^{19}$. A partir dessa análise, entendemos que as profissionais se protegem pelo "dispositivo da escrita", que é uma forma que desenvolvem para permanecer em relação, e não assujeitadas perante o poder médico.

No que diz respeito às relações desiguais de poder, observaram-se também cuidados distintos quanto à prevenção de eventos adversos, como no relato abaixo:

Isso daí é por baixo, isso foi simples, coisas muito graves aconteceram, como falar que a equipe é responsável pela morte de criança aqui dentro, a nível de infecção. E uma coisa assim, tipo uso de capote eu só não uso capote em último caso, quando não tem. E eu acho que... você viu a doutora manipular os pacientes sem capote? (Téc. 2) 
Identifica-se nesse relato o autogoverno dos médicos em relação aos demais profissionais e desigualdade nas relações de poder.

A descrição a seguir apresenta a observação anterior a essa entrevista:

A técnica de enfermagem fazia procedimentos de administração de remédios em uma criança, quando a médica chegou, a observou e perguntou em voz alta e tom austero: Você está seguindo o protocolo para administração dessa medicação? A técnica inibida respondeu afirmativamente. E a médica insistiu: "Estou perguntando se está seguindo o protocolo". A técnica confirmou após consultar a intranet. A técnica acenou para as demais colegas, demonstrando indignação. A médica era a única profissional que não usava capote no setor. (DB, p. 54)

Ante os confrontos interprofissionais com os médicos, os profissionais da enfermagem não se sentem reconhecidos e denunciam a forma como são cobrados, como no seguinte relato: "Eu acho que é mais falta de reconhecimento dos profissionais que a gente sente, porque a gente tá com eles todo dia, igual assim, uma frase que define muito a minha fala é... mil acertos, nenhuma parabenização, um erro, mil condenações" (E. 1).

Salienta-se que a busca de culpados pelos erros não contribui para a formação integral do profissional e para a autonomia e produz relações controladoras ${ }^{14}$, acirrando relações de insegurança e erros, como explicitado pela profissional: "É porque também tem erro demais, e o erro tem mais cobrança e, aumenta o erro, porque as meninas ficam tensas, elas ficam apavoradas como elas são tratadas" (E. 2).

Com relação aos enfermeiros, um estudo aponta que seu processo de trabalho, em uma unidade de terapia intensiva, é muito complexo, envolvendo gestão da equipe, do setor e capacitação da equipe técnica, além da assistência às crianças, o que fragiliza sua atuação. Perante a sobrecarga de trabalho, falta de condições e dificuldade da integração da equipe, esses profissionais assumem somente as funções gerenciais e os cuidados de alta complexidade, delegando os demais cuidados para os técnicos de enfermagem. No entanto, deveriam não só gerenciar, mas também realizar os cuidados diretos aos recém-nascidos e das necessidades de seus familiares ${ }^{18}$.

Diante da diversidade e complexidade de ações do enfermeiro, atualmente muitos hospitais têm reconfigurado seu papel, enfatizando a importância de sua atuação assistencial, e não mais a gerencial nessas organizações. O hospital em estudo passaria por essa mudança com a admissão dos concursados. O setor ficaria com alguns poucos técnicos para apoio e com os enfermeiros assistenciais.

Retomando a discussão acerca das diferenças hierárquicas entre os profissionais, a centralidade da responsabilização jurídica dos médicos também dificulta a integração da equipe. As exigências do Código Civil centralizam diversas cobranças nos médicos, abrangendo informações, diagnóstico, terapêutica e tratamento dos pacientes, inclusive a responsabilidade civil (com o paciente), que pode ser de ordem pessoal ou estrutural. No que tange à ordem pessoal, refere-se ao momento em que o profissional pode incorrer em erros por negligência, imperícia ou imprudência, enquanto a ordem estrutural refere-se aos momentos em que os meios e as condições de trabalho foram ineficazes ${ }^{20}$. Ressalta-se que a eficácia da terapêutica prescrita pelos médicos depende do trabalho dos demais profissionais, em especial da enfermagem. Apesar de os médicos possuírem destaque na hierarquia no poder decisório na UTIP, estão mais expostos a incorrerem em erros pela abrangência do Código Civil, fato que intensifica comportamentos controladores.

Por outro lado, as relações entre os profissionais de saúde não são somente conflitivas. Há solidariedade entre eles, como exemplificado pela observação descrita a seguir:

A técnica de enfermagem, enquanto cuidava de uma criança, que estava entubada, disse às profissionais do setor, em tom alto: "Quem estará de plantão no domingo?" Uma técnica e um médico responderam que estariam. A profissional propôs que todos levassem um lanche diferente para animar o setor. Logo, combinaram de levar bolo, sorvete e refrigerante. (DB, p. 57) 
Uma médica relatou durante a observação: "A gente sai junto. Eu saio sempre com a médica $X$. Temos que conversar fora daqui, porque o que a gente passa aqui dentro, só a gente entende, ninguém mais entende. A gente sofre muito, é muita pressão, mas a gente gosta demais do trabalho" (DB, p. 82).

Perante situações tensas, os profissionais eram mais solidários entre si, como perante a instabilidade orgânica das crianças, como na seguinte observação:

O setor estava silencioso, cada profissional estava em seu local de trabalho, algumas técnicas junto aos leitos das crianças, a enfermeira fazendo registros, o médico revendo prescrições no posto de enfermagem, ao centro da sala. De repente, em meio a tantos alarmes disparados, um chamou a atenção de todos. Todos profissionais interromperam o que estavam fazendo e se dirigiram para o leito daquela criança, sem conversar entre si. Logo começaram a intervir juntos e de modo integrado no corpo da criança. Quando os parâmetros de oxigenação apontaram estabilização, todos sorriram, e se cumprimentando pelo sucesso da intervenção. Lindo assistir um trabalho integrado assim! (DB, p. 82)

Esse fato aponta para a característica híbrida do setor, que possibilita conflitos, mas, ao mesmo tempo, relações solidárias e amistosas.

\section{O saber médico e o Cristianismo}

Ressalta-se que a tensão produzida pela dificuldade em lidar com a morte e com a dimensão subjetiva é fruto de uma formação dos profissionais que desvaloriza ou nega a subjetividade dos pacientes pela influência da ciência positivista no saber médico. Salienta-se que o saber médico influenciou a formação das demais profissões no campo da saúde. Nesse campo de saber, o controle da morte passa a ser objeto e o objetivo da ciência, pois os seres humanos passam a exigir da ciência médica o que antes esperavam da magia e da religião. O hospital é visto como o lugar onde se exclui a morte da sociedade, tanto pela cura quanto por seu distanciamento do convívio social21.

O fato de a morte se apresentar como algo abominável na UTIP, que deve ser evitado a todo custo, evidencia uma cultura de indivíduos-máquina, indivíduos que não podem errar. Aponta também para a negação da morte e da finitude, assim como para a negação do não saber, dos limites e da fragilidade dos seres humanos ${ }^{22}$.

O desenvolvimento científico e tecnológico distanciou a sociedade de lidar com a morte e, ao mesmo tempo, produziu um imaginário controle sobre ela ${ }^{22}$. O relato a seguir, do médico 3 , evidencia que a dificuldade em lidar com os limites dos procedimentos na UTIP tem se intensificado com o desenvolvimento tecnológico e científico.

Hoje é pior do que antes, porque você tem cada vez mais recursos, você sabe... entra no computador, ali enquanto você tá no plantão, e acha um artigo de revisão, eu posso fazer isso! Quer dizer, aí hoje, você tem que tirar aquele paciente e manter ele. Antes você tinha um limite e hoje não. O limite técnico é menos frequente, você vai ter um limite da pessoa. (M. 3 )

Essa enunciação elucida a ilusão do controle da ciência médica sobre a morte e da credibilidade nas possibilidades terapêuticas ${ }^{22}$. Essa forma de pensar traz dificuldades para os profissionais para lidarem com os limites terapêuticos e com seus próprios limites de ação, expondo-os ao sofrimento e a conflitos. Este outro relato exemplifica essa tensão: "Tem muito estresse. É um ambiente que a gente fica muito tenso, não é que não pode errar, e... algumas vezes não sai da forma correta, como deveria ser, isso pode causar tanto malefício por causa da situação aguda, que eu acho que cria muito estresse" (M. 3).

Ante a dificuldade em lidar com os limites na atuação profissional, após o óbito de uma criança, os profissionais relataram rever suas condutas e refletirem sobre seus atos, mas com sofrimento: "Em 
parte a cada situação clínica você tem que rever sua conduta clínica para aprender com possíveis erros, ou não, coisas melhores que podiam fazer, mas não precisava ser tão... com tanta culpa, mas aí não tem jeito, é o perfil das pessoas de se sentirem culpadas" (M. 3).

Entende-se que a obstinação terapêutica é resultado de um ethos irrefletido das carreiras biomédicas por associarem, erroneamente, a morte ao fracasso. Paradoxalmente, os profissionais de saúde lidam intensamente com a morte, mas resistem a reconhecê-la como fato inexorável da existência ${ }^{22}$. Nesse contexto, os profissionais sofrem por se sentirem culpados com a morte das crianças.

A influência do Cristianismo no Ocidente difundiu ideias de abdicação de si mesmo para dedicação ao outro e de práticas confessionais para purificação de si mesmo. O modelo cristão formado nos séculos III e IV produziu modos de se relacionar consigo mesmo a partir do conhecimento de verdades externas aos sujeitos com vistas ao alcance da vida eterna ${ }^{23}$. Esses ideais ascéticos induzem, ainda hoje, ao sentimento de culpa moralizante perante as condutas desviantes na sociedade ${ }^{23}$. $\mathrm{Na}$ enunciação a seguir, identificamos a regulação da relação do profissional consigo mesmo a partir do discurso do Cristianismo:

Tenho fé, mas não sou praticante, mas eu fui educado para ser, então isso está arraigado dentro de mim. E eu fico assim com aquele sentimento de culpa: será que eu fiz tudo pelo meu paciente? Não? Agora eu estudo e fiz tudo que era para ter feito, mas fico com esse sentimento. Mas, acho que é muito por causa disso, dessa minha educação católica. (M. 3)

A influência do Cristianismo associada à crença imaginária do saber e poder médicos no controle sobre a morte produzem acirramento de cobranças dos profissionais consigo mesmos e com os demais. Ademais, analisa-se que a relação entre profissional de saúde e paciente ainda mantém incorporado o antigo modelo do poder pastoral, com centralização da direção do cuidado nos profissionais ${ }^{23}$.

A enunciação desta outra profissional apresenta um pensamento racional de enfrentamento da ansiedade despertada no trabalho: "Então... para mim funciona é pensar que a gente tentou de tudo, a equipe tentou tudo e que, também a gente tem hora que... tem que saber a hora de parar, né? A vida tem um limite, né?" (Fisio. 2).

O fato de ter tentado tudo "o que poderia ser feito" denota um imaginário da possibilidade de controle sobre a morte nas práticas de trabalho na UTIP e as dificuldades em identificar os limites de atuação. Os profissionais se dedicavam tão intensamente ao trabalho que, muitas vezes, esqueciam-se de se cuidar. Alguns priorizavam o trabalho em detrimento das suas vidas pessoais.

Com relação aos médicos nesse setor, entende-se que a dificuldade com o limite de atuação pessoal e profissional dos pediatras pode ser analisada a partir da história dessa especialidade. A Pediatria surgiu com o compromisso de evitar a morte de crianças. A redução da mortalidade infantil é um indicador de qualidade de vida da população. Tal contexto contribui para a desnaturalização da morte de crianças $^{24}$.

Em outra direção, na multiplicidade de forças que operam no setor, em alguns momentos, observase que, em face do intenso envolvimento afetivo com as crianças, emerge uma nova ética no trabalho, como na seguinte observação: "Os profissionais passavam perto da criança $\mathrm{X}$ e brincavam com ela. Era uma criança com longo tempo de internação. A criança batia palmas quando os profissionais se aproximavam dela. Em alguns momentos, profissionais cantarolavam para a criança, que respondia com sorrisos" (DB, p. 71).

A partir do exposto, acreditamos que intervenções no setor podem transformar as formas de se relacionar entre os sujeitos, tanto consigo mesmo quanto com os outros, fortalecendo a integração da equipe, o que, por sua vez, estimula a autonomia e a responsabilidade no trabalho. Tais intervenções devem ser construídas com o grupo e considerar dispositivos que envolvam novos referenciais, de saberes e de práticas. 


\section{Considerações finais}

O sentimento de responsabilidade dos profissionais na UTIP é constituído mediante práticas de trabalho organizadas por mecanismos disciplinares, reguladas por leis e verdades provenientes do saber médico e jurídico, bem como pelos valores do Cristianismo, cenário em que a responsabilidade é convertida, muitas vezes, em sentimento de culpa. Tal sentimento moralizante produz sofrimento e conflitos nas relações entre os profissionais.

Salienta-se que, nesse setor, os profissionais de saúde lidam com crianças em situação crítica e com práticas terapêuticas intervencionistas e invasivas nos corpos orgânicos, com riscos de efeitos iatrogênicos. Em contrapartida, confrontam-se constantemente com a possibilidade de denúncias jurídicas dos pais das crianças ou até mesmo dos profissionais entre si, em função da difusão dos direitos sociais por parte do Estado e pelo interesse do mercado corporativo. Evidencia-se um aumento do número de processos judiciais contra os erros médicos e dos profissionais de saúde, intensificando os mecanismos de vigilância sobre estes.

Na micropolítica das relações, observam-se comportamentos perfeccionistas. Salienta-se que o impacto da possibilidade de erros profissionais produz um nível de exigência muito elevado nas relações dos profissionais consigo mesmos e com os demais, como se fossem máquinas infalíveis, e não seres humanos. Ressalta-se a importância de intervenção no setor a fim de estimular reflexões críticas sobre o trabalho para novos posicionamentos e integração da equipe.

\section{Colaboradores}

Os autores participaram igualmente da discussão dos resultados, revisão e aprovação da versão final do trabalho.

\section{Agradecimentos}

À Coordenação de Aperfeiçoamento de Pessoal de Nível Superior (Capes), fundação do Ministério da Educação (MEC) e ao Conselho Nacional de Desenvolvimento Científico e Tecnológico (CNPq).

\section{Referências}

1. Verdi $M$, Finkler $M$, Matias MCS. A dimensão ético-estético política da humanização do SUS. Epidemiol Serv Saúde. 2015; 24:363-72.

2. Ministério da Saúde (BR). HumanizaSUS (2009): documento base para gestores e trabalhadores do SUS. 4a ed. Brasília; 2009.

3. Foucault M. Segurança, território, população. São Paulo: Matins Fontes; 2008. 
4. Guattari F, Rolnik S. Micropolítica. Cartografia do Desejo. 7a ed. Rio de Janeiro: Vozes; 2005.

5. Vasconcelos C. Responsabilidade médica e judicialização na relação médico-paciente. Rev Bioet. 2012; 20:389-96.

6. Cardoso CG, Hennington EA. Trabalho em equipe e reuniões multiprofissionais de saúde: uma construção à espera pelos sujeitos da mudança. Trab Educ Saude. 2011; 9 Supl 1:85-112.

7. Ferreira Neto JL, Kind L, Pereira AB, Rezende MCC, Fernandes ML. Usos da noção de subjetividade no campo da Saúde Coletiva. Cad Saude Publica. 2011; 27(5):831-42.

8. Minayo MCS. O desafio do conhecimento: pesquisa qualitativa em saúde. 12a ed. São Paulo: Hucitec; 2010.

9. Castro E. Vocabulário de Foucault - um percurso pelos temas, conceitos e autores. Belo Horizonte: Autêntica; 2009.

10. Schraiber LB. Ética e subjetividade no trabalho em saúde. Saude Debate. 1996; 12:45-50.

11. Schraiber LB. No encontro da técnica com a ética: a exercício de julgar e decidir no cotidiano do trabalho em medicina. Interface (Botucatu). 1997; 1(1):123-40.

12. Carvalho BR, Ricco RC, Santos R, Campos MAF, Mendes ES, Mello ALS, et al. Erro médico: implicações éticas, jurídicas e perante o código de defesa do consumidor. Rev Cienc Med. 2006; 15(6):539-46.

13. Peixoto TC, Brito MJ. Protocolos clínicos como dispositivo analítico das relações de poder em uma Unidade de Terapia Intensiva Pediátrica. Saude Debate. 2015; 39(107):1053-64.

14. Vargas MAO, Ramos FRS. Responsabilidade no cuidar: no tempo que nos toca viver com enfermeiros(as) intensivistas. Rev Esc Enferm USP. 2011; 45(4):876-83.

15. Nascimento $C A D$, Silva $A B$, Silva $M C$, Pereira $M H M$. A Significação do óbito hospitalar para enfermeiros e médicos. Rev RENE. 2006; 7(1):52-60.

16. Carapinheiro G. Saberes e poderes no hospital: uma sociologia dos serviços hospitalares. Porto: Afrontamento; 1988.

17. Araújo LFS. Processos de subjetivação inscritos na constituição da experiência de si da/o enfermeiro nas práticas assistenciais de um cenário de trabalho exemplar: a Unidade de Terapia Intensiva [tese]. Ribeirão Preto (SP): Escola de Enfermagem de Ribeirão Preto, Universidade de São Paulo; 2005.

18. Montanholi LL, Merighi MAB, Jesus MCP. Atuação da enfermeira na unidade de terapia intensiva neonatal: entre o ideal, o real e o possível. Rev Lat-Am Enfermagem. 2011; 19(2): [8 telas].

19. Foucault M. Vigiar e punir: nascimento da prisão. Petrópolis: Vozes; 1987.

20. Oliveira DU. A responsabilidade civil por erro médico [Internet]. Rio Grande. In: Âmbito Jurídico. 2008 [citado 21 Out 2016]; 9(59). Disponível em: http://www.ambitojuridico.com.br/site/?n_link=revista_artigos_leitura\&artigo_id $=3580$

21. Foucault M. O nascimento da clínica. Rio de Janeiro: Forense Universitária; 1977.

22. Diniz D. Quando a morte é um ato de cuidado: obstinação terapêutica em crianças. Cad Saude Publica. 2006; 22(8):1741-8.

23. Foucault M. A Hermenêutica do sujeito. São Paulo: Matins Fontes; 2004.

24. Pereira JS. História da pediatria no Brasil de final do século XIX a meados do século XX [tese]. Belo Horizonte (MG): Faculdade de Filosofia e Ciências Humanas, Universidade Federal de Minas Gerais; 2006. 
Peixoto TC, Passos ICF, Brito MJM. Responsabilidad y sentimiento de culpa: una vivencia paradójica de los profesionales de terapia intensiva pediátrica. Interface (Botucatu). 2018; 22(65):461-72.

El objetivo de este estudio fue analizar la constitución de la responsabilidad en el trabajo de profesionales de salud en una unidad de cuidados intensivos pediátrica. La encuesta es de abordaje cualitativo con colecta de datos por medio de entrevistas con guion semiestructurado a un grupo heterogéneo de 14 profesionales. Se realizaron observaciones sistemáticas en diversos horarios de trabajo, en un total de ochenta horas, registradas en un diario de a bordo. El análisis del discurso se fundamentó en la perspectiva foucaultiana. A partir de este estudio, se señala que el sentimiento de responsabilidad es convertido en sentimiento de culpa por parte de los profesionales, a partir de un entrelazamiento de regímenes de verdades provenientes de los campos del poder judicial, del Cristianismo y el saber médico que inciden sobre las prácticas. Las dificultades para enfrentar límites en la actuación profesional desencadenan conflictos interprofesionales generadores de sufrimiento al enfrentar la muerte de niños.

Palabras clave: Relaciones inter-profesionales. Responsabilidad profesional. Ética profesional. 